\title{
USE OF UBIQUITOUS TECHNOLOGIES IN MILITARY LOGISTIC SYSTEM IN IRAN
}

\author{
P. Jafari ${ }^{\text {a }}$, A. Sadeghi-Niaraki ${ }^{\text {a }}$ \\ ${ }^{\text {a }}$ GIS Dept. Faculty of Geodesy and Geomatics Eng, K.N.Toosi Univ. of Tech., Tehran, Iran - \\ peiman.j1369@gmail.com, a.sadeghi@kntu.ac.ir
}

Keywords: GIS, military logistic system, RFID, supply chain management

\begin{abstract}
:
This study is about integration and evaluation of RFID and ubiquitous technologies in military logistic system management. Firstly, supply chain management and the necessity of a revolution in logistic systems especially in military area, are explained. Secondly RFID and ubiquitous technologies and the advantages of their use in supply chain management are introduced. Lastly a system based on these technologies for controlling and increasing the speed and accuracy in military logistic system in Iran with its unique properties, is presented. The system is based on full control of military logistics (supplies) from the time of deployment to replenishment using sensor network, ubiquitous and RFID technologies.
\end{abstract}

\section{INTRODUCTION}

Military supplies are the vital part of any military operations and the results of the war are greatly influenced by replenishment of supplies. The effectiveness of using ubiquitous and RFID technologies in supply chain management have been shown in many studies. To increase the speed and accuracy in logistic system management, a revolution by the mean of using ubiquitous and RFID technologies seems to be a must. In this study supply chain management and necessity for change in military logistic systems, are described and then we point out the researches done on these technologies and the common usage of them. There are many benefits in using these technologies in supply chain management and some of them are mentioned.

Reduction of inventory losses, increase of the efficiency of process and improvement of information accuracy are the main perks of using RFID technologies. Different type of RFID systems can be made by combining different tags, readers, frequencies and level of tagging, etc.

All military weapons, vehicles, supplies, and ammunitions that are RFID installed military supplies, can be connected to the delivery route information to calculate the optimal path for delivery of supply. The supply units will be able to recognize the necessary supplies for each consuming units so that the delivery of supplies will be more effective in future. By using a chip all military supplies can be controlled throughout processes such as production, supply, transportation, stock management, repair management and disposal.

The construction of ubiquitous logistic supply system using RFID chip leads to scientific management of the military logistic by allowing combined management of all logistic supply networks, optimizing supply cycles from the supply quarter to troops and enhances supply organs through efficient management of information among military supply management and unit-supply.

In the next part of the study, the challenges of using these technologies are explained and lastly a system based on these technologies using logistic system management for Iran is designed.

Iran is in a strategic area in Middle East and there is a need for a change in logistic management and military forces are no different. The system, using these technologies advantages, is designed in a way that covers all required steps for logistic system management in Iran. This system is debugged as much as possible from common flaws in order to control supply chain management in military area fast and accurately.

\section{SUPPLY CHAIN MANAGEMENT}

SCM is defined as a strategic method that maximizes benefits and advantages of the whole supply chain network by using interfaces of chains and cooperative coordination of parties involved with an overall perspective on the flow of information, material, and money in the supply chain (D. Lambert., 2008). The application of the SCM concept for the construction industry is a must in order to eliminate uncertainties in the construction supply chain, to improve efficiency in time and revenue by increasing prefabrication of building components and materials, and to build an integrated system between supply chain and the construction site to react to design changes more effectively and efficiently (R. Vrijhoef \& L. Koskela., 2000). Supply chain management research is a complex operation, which requires a carefully defined approach. In addition, complex technological researches become more dynamic and complex to solve. Consequently, it is also easy for different situations existing in a supply chain to get lost in the details and to spend a large amount of effort and time analysing the total system (Chin, Pei \& Pei., 2010).

\section{THE NEED TO REVOLUTIONIZE THE ARMY LOGISTICS SYSTEM}

To fulfil the support needs of an army in this new era, army 
logistics system has become leaner, more flexible, and more responsive: leaner because defence budgets will no longer gives the army the ability to maintain a massive logistics system; more flexible because the army must prepare for a wide range of potential contingencies rather than focusing on a specific area; and more responsive because of increased uncertainty regarding the nature of the threat and because neither forward positioning nor host nation support can be assumed (John Dumond, Rick Eden \& John Folkeson ., 1994).

\section{CLASSIFICATION OF MILITARY SUPPLIES}

Military supplies are classified according to the number of pieces, nature (expendables and non-expendables), unit prices (high and low), and so on. There are various standards but classification based on their kinds is used most common. In this study, military supplies are classified based on their kinds. An example is added below in Table 1 (www.GlobalSequrity.org).

\begin{tabular}{|l|l|}
\hline \multicolumn{1}{|c|}{ CLASSES } & \multicolumn{1}{|c|}{ SUBCLASSES } \\
\hline Class I - Subsistence & A - Nonperishable \\
& C - Combat Rations \\
& R - Refrigerated \\
& S - Other Non-refrigerated \\
W - Water \\
\hline Class II - Clothing, & A - Air \\
Individual Equipment, Tools, & B - Ground Support Materiel \\
Admin. Supplies & E - General Supplies \\
& F - Clothing \\
& G - Electronics \\
& M - Weapons \\
& T - Industrial Supplies \\
\hline Class III - Petroleum, Oils, & A - POL for Aircraft \\
Lubricants & W - POL for Surface Vehicles \\
& P - Packaged POL \\
\hline Class IV - Construction & A - Construction \\
Materials & B - Barrier \\
\hline Class V - Ammunition & A - Air Delivery \\
& W - Ground \\
\hline Class VI - Personal Demand & \\
Items & \\
\hline Class VII - Major End Items: & A - Air \\
Racks, Pylons, Tracked & B - Ground Support Materiel \\
Vehicles, Etc. & D - Admin. Vehicles \\
& G - Electronics \\
\hline Class VIII - Medical & A - Racks, Adaptors, Pylons \\
Materials & K - Tactical Vehicles \\
\hline Class IX - Repair Parts & L - Missiles \\
& M - Weapons \\
& A - Special Weapons \\
& B - Ground Support Materiel \\
& D - Admin. Vehicles \\
G - Electronics \\
K - Tactical Vehicles \\
L - Missiles \\
M - Weapons \\
N - Special Weapons \\
\hline
\end{tabular}

\begin{tabular}{|l|l|}
\hline & X - Aircraft Engines \\
\hline $\begin{array}{l}\text { Class X - Material For Non- } \\
\text { military Programs }\end{array}$ & \\
\hline
\end{tabular}

Table 1. Classification Class I -Class X

\section{UBIQUITOUS ENVIRONMENT}

\subsection{RFID (Radio Frequency Identification)}

Radio frequency identification (RFID) has become an important topic in the fields of manufacturing and logistics. It has emerged as part of a new form of inter-organizational system that aims to improve the efficiency of the processes in the supply chain (E.W.T. Ngai, Karen K.L. Moon, Frederick J. Riggins \& Candace Y. Yi., 2006). RFID is a small tag containing an integrated circuit chip and an antenna, and has the ability to respond to radio waves transmitted from the RFID reader in order to send, process, and store information (N.C. Wu, M.A. Nystrom, T.R. Lin \& H.C. Yu., 2006). A typical RFID system includes tags and readers, application software, computing hardware, and middleware (E.W.T. Ngai, Karen K.L. Moon, Frederick J. Riggins \& Candace Y. Yi., 2006). RFID is an area of automatic identification that is gaining momentum and is considered by some to emerge as one of the most pervasive computing technologies in history. In its simplest form, RFID is a similar concept to bar coding. It is seen as a way of enhancing data processes and is complementary to existing technologies. A more complex description is an electromagnetic proximity identification and data transaction system. Installing RFID tags on objects or assets, and readers to collect the tag information, RFID reveals more advantages over bar codes in terms of non-optical proximity communication, information density, and two-way communication ability. Operational RFID systems involve tags and readers interacting with objects (assets) and database systems to provide an information and operational function (C.M. Roberts., 2006). The RFID middleware filters data from readers to avoid information overloading, ensures data accuracy, and feeds enterprise resource planning (ERPs) systems with data to control and manage their business systems and operations. Therefore, RFID overcomes the shortfalls of individual manual tracking systems in storing, tracking, wirelessly identifying and communicating information without the need for the object to be within the line-of-sight (Lee \& Lee., 2011).

\subsection{Ubiquitous sensor network}

RFID is, the Main Technology of USN. Sensor Network is the information management that detects the condition of an item (the temperature, humidity, degree of contamination, a crevice, etc.) by attaching an RFID tag to it and sending the information to the network. Ultimately, all the objects are endowed with computing and communication abilities regardless of time, places, where, net-works, devices, and services. In order to have a better understanding of USN, various RFID tags that offer sensor information should be developed as well as sensing functions so as to build networks among them. USN is a technology that gives the ability of communication through different broadband networks regardless of wired/wireless and telecommunication broadcasting. The technology is available anytime and anywhere through varying telecommunication 
devices such as a desktop computer, a mobile PC, a mobile phone, a PDA, a car navigation terminal, and information appliances. The number of terminals given an ID by IPv6 is on the rise, allowing users to connect to networks anytime anywhere. Since it is a barrier-free interface, people of all ages, even the disabled can use without any difficulty (Sung-Min Yang., 2003; www.ukoreaforum.or.kr).

\section{POTENTIAL BENEFITS OF RFID TECHNOLOGIES IN SUPPLY CHAINS}

The benefits of using RFID technologies in supply chain management have been provided by many different researchers in different studies. RFID technologies provide several benefits to supply chain via their special properties such as unique identification of products, easiness of communication and real time information (Saygin, C., 2007; Michael, K., McCathie, L., 2005). By integrating this technology, tracking, shipping, checkout and counting, becomes more reliable and faster as the technology provides accurate and timely data for managing the information flows that leads to improved material flow and inventory management (Dai \& Tseng., 2012). In addition, RFID systems offer some kind of supply chain-related data and information that are used for improving the planning and control of supply chain operations (Ngai, To, Moon, Chan, Yeung \& Lee., 2010). There are three major problems of supply chain management that can be overcome through RFID; inventory inaccuracy, the bullwhip effect and replenishment policies (Aysegul SARAC, Nabil ABSI, Stéphane DAUZEREPERES., 2009).

Li and Visich (2006) have mentioned 39 and May Tajima 15, benefits of using RFID technologies. The 15 benefits mentioned by May Tajima are sorted into two main groups: (i) the benefits that can be realized throughout the supply chain, and (ii) the benefits that can be realized by major supply chain participants (May Tajima., 2007). Companies could have better supply chain planning and management by integrating and storing more accurate data gained through RFID technologies in their information technology systems (Whitaker, Mithas, \& Krishnan., 2007). Reengineering models can make such a great difference in potential benefits made through RFID for all processes of distribution centers and retailers (Bottani \& Rizzi., 2008). Ferrer, Dew, and Apte (2010) studied 21 RFID applications across a wide variety of industries. They came to the conclusion was that there were four common benefits: replacement of labour through automation, cycle time reduction, enabling self-service, and loss of prevention. Via these great benefits, RFID technologies can provide cost reduction, increased savings, process improvement, service quality, etc. A system using RFID can provide real-time information to operators, managers, and supervisors in order to control actual situation in the supply chain. Thus, they can manage customers' demands and adjust the production plan timely to improve the whole supply chain efficiency and effectiveness (Cheung, Cheung \& Kwok., 2012). ROI analyses are used to support decisions on the possibility of RFID deployments (Fleisch \& Tellkamp., 2005). For managers and professionals, it was very important to accurately measure the benefits of an RFID project in the planning phase. Using the most proper investment evaluation methods, the managers can take the accurate decisions on RFID implementation projects (Ustundag, K1lınc \& Cevikcan., 2010). Net present value and ROI were commonly used to evaluate investment in new technologies. As there existed RFID technology uncertainties and risks such as global standardization, chip price, security and privacy and high investment costs, an accurate economic analysis prior to investment should be made (Lee \& Lee., 2011). The factors of product value and demand uncertainty have a considerable impact on the potential benefits of RFID integrated systems. The more the product value increases the more total supply chain cost savings get, and the increased demand uncertainty decreases the supply chain cost savings. The results also demonstrated that each member of the supply chain does not benefit equally from RFID integration. The retailer has the highest cost savings, and the lost sales cost factor has a high impact on the integrated RFID supply chain (Alp Ustundag \& Mehmet Tanyas., 2009).

Replenishment is crucial in safeguarding customer service with the minimum inventory holding costs. The real-time data of RFID provide companies an asset for developing advanced and intelligent replenishment policies that manual or barcodebased systems do not provide (Condea, Thiesse, Fleisch., 2012).

\section{CHALLENGES AND ISSUES IN RFID ADOPTION}

Many studies have been carried out on challenges of using RFID technologies and the methods to overcome or improve these challenges. May Tajima has mentioned a number of these challenges: a lack of return on investment (ROI), technical risks, the popularity of bar codes, and privacy concerns (May Tajima., 2007).

The major problems can be broken down into technology challenges, standard challenges, patent challenges, cost challenges, infrastructure challenges, return on investment (ROI) challenges, and barcode to RFID migration challenges (N.C. Wu, M.A. Nystrom, T.R \& Lin, H.C. Yu., 2006) .Policy, security, and standard challenges are of most importance and should not be neglected under any circumstances.

\section{METHODOLOGY}

\subsection{Management of military logistics in Iran}

Iran has two different military forces: The Islamic Republic of Iran Army (IRIA) also called Artesh, and the Islamic Revolutionary Guard Corps (IRGC) known as Pasdaran. During the 8-year lasting war between Iran and Iraq, these forces: Artesh and Sepah fought cooperatively. In this study In order to cover the cooperation of Artesh and Sepah, the garrisons of both forces are presumed as stock center and supply units.

Iran is the seventeenth largest country in the world and located in a special geographical area. Being bordered by multiple countries makes Iran a potential war target especially from east and west. Moreover, Iran borders Persian Gulf and sea of Oman on the south thus the country needs protection from south. Iran's mentioned unique properties demand a fast and accurate distribution of military logistics (supplies).

Production and distribution centers should be located in proper positions and optimal paths should be determined so that the distribution task is done in the fastest and most accurate yet cheapest way possible.

Consumption of military logistics (supplies) should be reported to distribution centers as fast as possible and the distribution 
center should send the logistics (supplies) from production center to supply unit. RFID technologies are used to make the process faster and more accurate. Different stages of this study are explained below:

\subsection{Stage one}

We can determine the status of all garrisons (type and number of pieces of weapons and so on) by connecting RFID tags to all existing logistics (supplies) in garrison stocks. Logistics (supplies) leaving the stock for deployment should pass a manual_reader or a gate with a reader installed on the it so that the information of the tag is read and the date of departure is sent to a server in distribution center. The information stored on a tag includes logistics type, garrison name, main distribution center and production center.
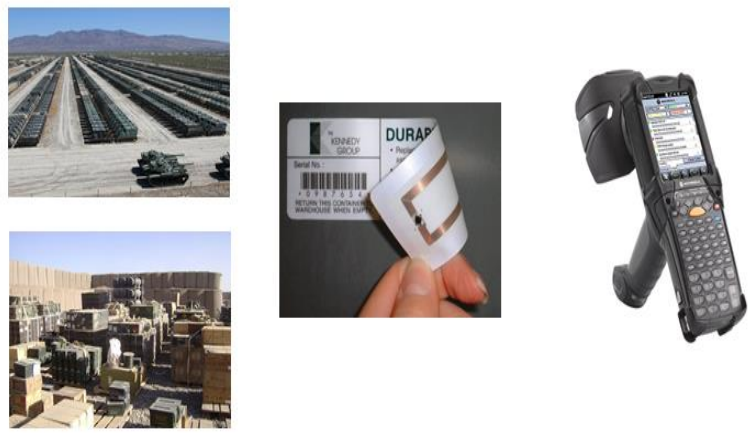

Figure 1. Connecting RFID tags to all military logistics (supplies) in all garrisons in order to control incoming and outgoing logistics via readers.

\subsection{Stage two}

By using GIS methods, distribution centers are located in proper locations. Operating range of each distribution center should also be determined. Each distribution center is only able to control readers in its own range and all readers in this range are only controlled by that distribution center. A local USN or another distribution center cannot access the readers as they can only communicate with that distribution center to access information. All USNs are under control of one domestic USN in order to prevent duplicate reading and some potential problems that are related to using RFID technology. For each installed reader in various part of the country, there is only one controlling center. This will enhance the security of distribution process tremendously. Main distribution center is determined by the range in which the reader is located. Whenever a supply leaves a garrison, its production center gets determined.

If the production center is within the range of the distribution center, all of the distribution process will be under control of that main distribution center otherwise according to the location of production centers, garrison, operating range of different distribution centers and the location of distributing centers throughout the path from production center to garrison, main distributing center will determine the type and path of transferring of the supply from production center to garrison. Timing is one the most essential factor when choosing the optimal path.
The mean of transportation should also be determined in order to ease cooperation between centers. Readers should be installed in airports, train stations, specific part of roads, marinas, etc. in specific places manual readers could be used for reading tags. According to which operating range the supple is at any time, a distribution center will control the supply.

So in general the main distribution center determines the path, type of transportation, the certain amount of time needed for the supply to travel from production center to garrison, the readers throughout the path and the date when supplies will pass the readers.

By integrating RFID tags, distribution timing could be precisely made so that the garrison will receive the supplies on demanded time. The amount of time from departure to arrival of supply depends on the military logistics category and plays an important role for distribution planning.

In the planning, the time and the place where logistics (supplies) meat the readers are determined thus when there is a problem and the reader doesn't send back the expected logistics (supplies) information, it is realized that from the last reader that sent information to the server to this reader something has gone wrong in distribution process. All steps of distribution process could be followed in great detail via RFID technology.

As mentioned before, to prevent any security problem, the information read by each reader is only accessible by a local controller but in a network that covers all country, the main distribution center should determine the distribution centers it needs to communicate with to access the information of the tags that are not in its operating range. The main distribution center can access the information of those readers temporarily and when the distribution is over, the access will be denied. In fact all local networks should work under one domestic USN so that two or more local network can communicate (share information) if needed. Once the distribution process is over, the USN ends the access between the networks in order to prevent any network speed or security issues.
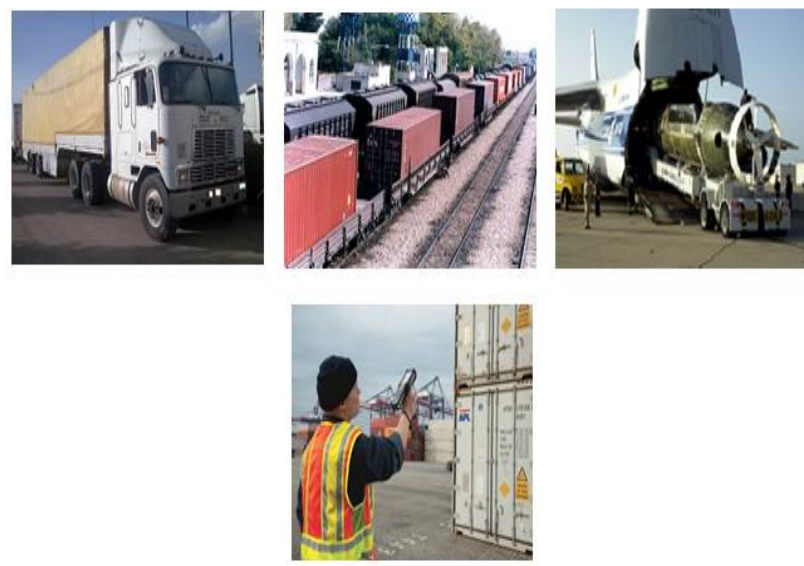

Figure 2. Determining the mean of transportation by the main distribution center and reading the information of truck tags from distance by readers

The flow chart shows the steps of supply management cycle of military logistics via RFID and ubiquities technologies: 


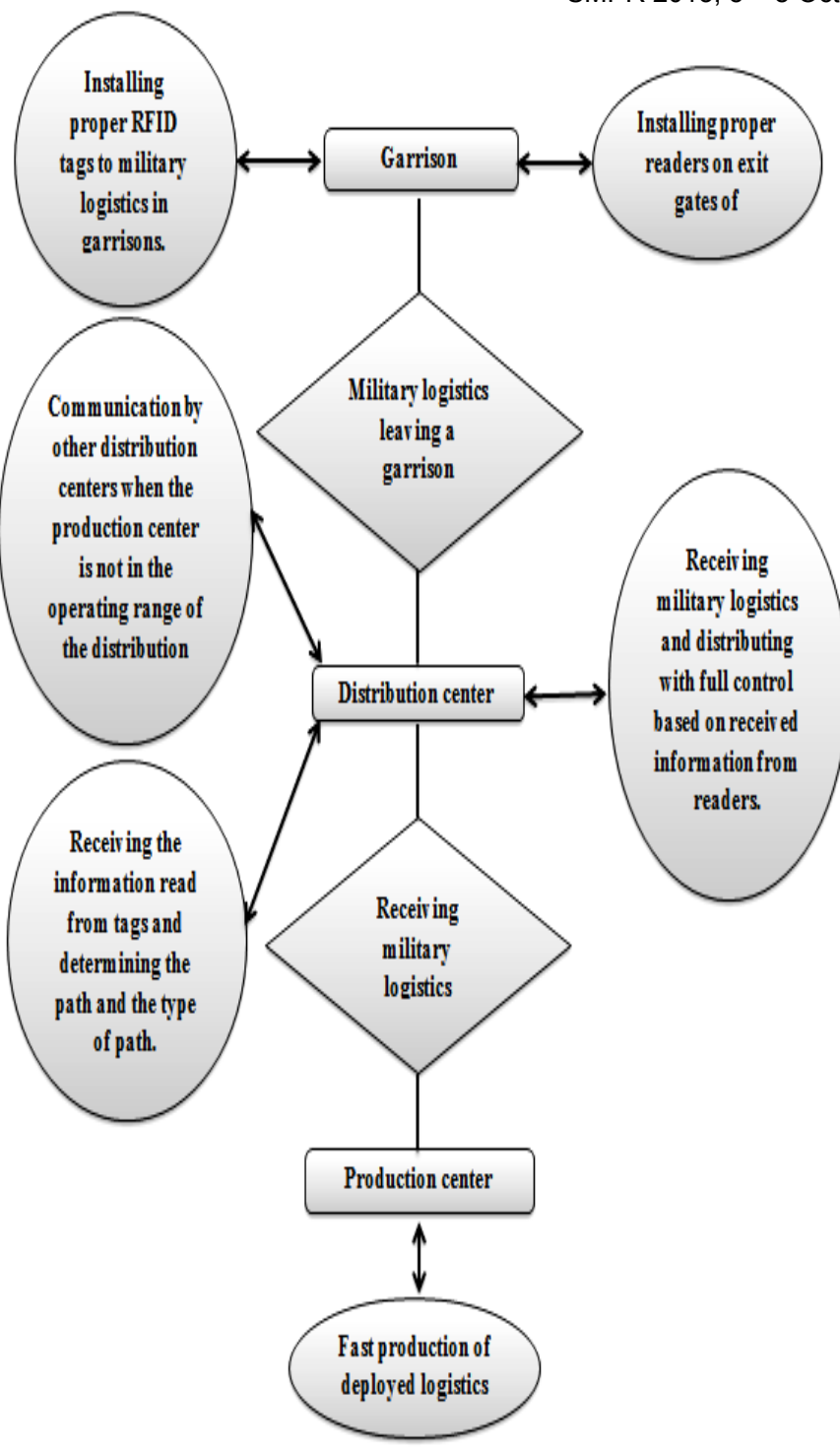

Figure 3. Cycle of military logistics via RFID

\section{CONCLUSION}

In this study, we mention the effectiveness of ubiquitous and RFID technologies and the necessity for a revolution in military logistic systems and then a fully practical system using these technologies for Iran, is analysed and explained in a great detail.

Through this study, it was explained that it is possible to manage the whole cycle throughout the path fast, accurately and with full control via ubiquitous and RFID technologies. It was also shown that by having local networks, and precise control of readers, we can have any security issues under control and the connection between these networks are control by one main domestic network so that the information read from tags are kept secure thus the advantages of these technologies are used as the potential problems are kept at a minimum.

Results of this study performed on Iran garrisons show that ubiquitous technology and RFID in military supplies model has had a great impact and increased the efficiency and speed of process and improved the information accuracy.

In the future researches, the precise information of the production centers could be obtained so that the selection of production centers is done in a real time mode not in a preset fashion.

\section{REFERENCES}

Alp Ustundag, Mehmet Tanyas., 2009. The impacts of Radio Frequency Identification (RFID) technology on supply chain costs.

Aysegul SARAC, Nabil ABSI, Stéphane DAUZERE-PERES., 2009. Ecole des Mines de Saint-Etienne, CMP - Site Georges Charpak 880, Avenue de Mimet F-13541 Gardanne France.

Bottani, E., Rizzi, A., 2008. Economical assessment of the impact of RFID technology and EPC system on the fast-moving consumer goods supply chain. International Journal of Production Economics, 112, 548-569.

Cheung, C. F., Cheung, C. M., Kwok, S. K., 2012. A knowledge-based customization system for supply chain integration. Expert Systems with Applications, 39,3906-3924.

Chin-Yuan Fan, Pei-ShuFan, Pei-ChannChang., 2010. A system dynamics modeling approach for a military weapon maintenance supply system.

C.M. Roberts., 2006. Radio frequency identification (RFID), Department of Information Sciences, Otago University, New Zealand.

Condea, C., Thiesse, F., Fleisch, E., 2012. RFID-enabled shelf replenishment with backroom monitoring in retail stores. Decision Support Systems, 52(4), 839-849.

Dai, H., Tseng, M. M., 2012. The impacts of RFID implementation on reducing inventory inaccuracy in a multistage supply chain. International Journal of Production Economics, 139(2), 634-641.

D. Lambert., 2008. Supply Chain Management: Processes, Partnerships, Performance, Supply Chain Management Institute.

E.W.T. Ngai, Karen K.L. Moon, Frederick J. Riggins, Candace Y. Yi., 2006. RFID research: An academic literature review (1995-2005) and future research directions.

Ferrer, G., Dew, N., \& Apte, U., 2010. When is RFID right for your service? International Journal of Production Economics, $124,414-425$.

Fleisch, E., \& Tellkamp, C., 2005. Inventory inaccuracy and supply chain performance: A simulation study of a retail supply chain. International Journal of Production Economics, 95, 373385 .

John Dumond, Rick Eden , John Folkeson ., 1994. Weapon System Sustainment Management .

Lee, I., \& Lee, B., 2010. An investment evaluation of supply chain RFID technologies: A normative modeling approach. 
International Journal of Production Economics, 125(2), 313323.

Lee, Y. C., Lee, S. S., 2011. The valuation of RFID investment using fuzzy real option. Expert Systems with Applications, 38, 12195-12201.

May Tajima., 2007. Strategic value of RFID in supply chain management, Management and Organizational Studies, The University of Western Ontario, London, Ontario, Canada N6A $5 \mathrm{C} 2$.

Michael, K., McCathie, L., 2005. The pros and cons of RFID in supply chain management. In: Proceedings of the International Conference on Mobile Business, pp. 623-629.

N.C. Wu, M.A. Nystrom, T.R. Lin, H.C. Yu., 2006. Challenges to global RFID adoption, Institute of Technology Management, Chiao-Tung University, 1001Ta-Hsueh Road, Hsinchu 300, Taiwan.

Ngai, E. W. T., To, C. K. M., Moon, K. K. L., Chan, L. K., Yeung, P. K. W., \& Lee, M. C. M., 2010. RFID systems implementation: A comprehensive framework and a case study. International Journal of Production Research, 48(9), 2583 2612.

R. Vrijhoef, L. Koskela., 2000. The four roles of supply chain management in construction, European Journal of Purchasing \& Supply Management 6 (2000) 169-178.

Saygin, C., 2007. Adaptive inventory management using RFID data. The Interna- tional Journal of Advanced Manufacturing Technology 32, 1045-1051.

Sung-Min Yang. , 2003. The Optimization for SCM with RFID Technology Journal of Engineering Science and Technology, Vol.2 No.2.

Ustundag, A., Kılınc, M. S., \& Cevikcan, E., 2010. Fuzzy rulebased system for the economic analysis of RFID investments. Expert Systems with Applications, 37,5300-5306.

Whitaker, J., Mithas, S., \& Krishnan, M. S., 2007. A field study of RFID deployment

return expectations. Production and Operations Management, 16, 599-612.

References from websites:

http://www.GlobalSequrity.org.

ubiquitous IT Korea forum :

http://www.ukoreaforum.or.kr/ukorea/index.php . 